УДК 547.992.3

\title{
РАСТВОРЕНИЕ ДРЕВЕСИНЫ В ИОННЫХ ЖИДКОСТЯХ НА ОСНОВЕ ИМИДАЗОЛИЯ
}

\author{
() Т.Э. Скребеи", А.Д. Ивахнов \\ Северный (Арктический) фредеральный университет им. М.В. Ломоносова, \\ набережная Северной Двины, 17, Архангельск, 163002 (Россия), \\ e-mail: tskrebets@mail.ru
}

\begin{abstract}
Изучена динамика растворения древесины ели обыкновенной (Picea abies) в ионных жидкостях (ацетат 1-бутил-3-метилимидазолия и хлорид 1-бутил-3-метилимидазолия) в интервале температур от 80 до $160{ }^{\circ} \mathrm{C}$. Установлено, что ацетат 1-бутил-3-метилимидазолия обладает лучшей растворяющей способностью по отношению к древесине, чем хлорид 1-бутил-3-метилимидазолия, при температурах $80-135^{\circ} \mathrm{C}$. При температуре $160{ }^{\circ} \mathrm{C}$ еловая древесина почти полностью растворяется в ацетате 1-бутил-3-метилимидазолия, однако растворение древесины при этой температуре приводит к деструкции ее компонентов. Из раствора, полученного путем обработки древесины ацетатом 1-бутил-3метилимидазолия при $120^{\circ} \mathrm{C}$ в течение 2 ч, селективно выделены лигнин и углеводная фракция древесного вещества, в ИК-спектрах регенерированных образцов присутствуют характеристические полосы соответствующих компонентов древесины. Анализ полимолекулярных свойств регенерированного из раствора лигнина показал, что в этих условиях деструкции его не происходит, и по величинам молекулярных масс и степени полидисперсности он близок к диоксанлигнину, выделяемому из древесины экстракцией диоксаном в мягких условиях.
\end{abstract}

Ключевые слова: древесина, ионные жидкости, растворение, температура, лигнин, целлюлоза.

\section{Введение}

Ожижение (растворение) древесины ионными жидкостями представляет собой один из способов химической конверсии растительной биомассы в полезные химические вещества, наряду с процессами делигнификации (удаление лигнина из древесины при высоких температуре и давлении с целью получения волокнистых целлюлозных материалов), газификации (термическое разложение древесины для получения биотоплива) и гидролиза (кислотная или энзиматическая обработка с целью получения сахаров) [1]. Учитывая растворяющую способность и совместимость ионных жидкостей с большим количеством органических и неорганических веществ и полимеров, можно утверждать, что исследование этого процесса создает предпосылки к разработке новых решений для преобразования древесной биомассы в ценные биотоплива, химические вещества и функциональные композиционные биоматериалы, а также предлагает новые возможности для ее структурной и макромолекулярной характеристики без предварительного выделения отдельных компонентов.

Древесина, обладая сложной структурой, обусловленной наличием взаимопроникающих сеток трех основных ее компонентов - целлюлозы, лигнина и гемицеллюлоз, не растворяется в обычных растворителях. Перевести ее в раствор можно, используя системы фенол - минеральная кислота [2] и фенол - многоатомный спирт [3] при повышенных температурах. Одна из первых опубликованных работ по растворению древесины ионными жидкостями [4] была посвящена сравнению их действия на древесину с разжижающей

Скребеи Татьяна Эдуардовна - профессор кафедры теоретической и прикладной химии, кандидат химических наук, e-mail: tskrebets@mail.ru

Ивахнов Артем Дмитриевич - научный сотрудник Центра коллективного пользования научным оборудованием «Арктика», кандидат химических наук, e-mail: ivahnov-tema@yandex.ru способностью системы фенол - серная кислота. Исследование влияния температуры, продолжительности, гидромодуля показало, что разжижающая способность анализируемых систем увеличивается, причем при любом значении варьируемых параметров ионная жидкость (хлорид диметил-

\footnotetext{
* Автор, с которым следует вести переписку.
} 
имидазолия) дает лучший по сравнению с традиционной системой результат. Ключевой момент перевода древесины в жидкое состояние - разрушение водородных связей в целлюлозе, обладающей высокой степенью кристалличности. Эту задачу, по мнению авторов, решают анионы ионных жидкостей, способные взаимодействовать с гидроксильными группами.

Впоследствии ученые сконцентрировали усилия на изучении действия на древесину именно хлорида имидазолия с различными заместителями [1].

В работе Килпелайнена [5] проведено более подробное обсуждение механизма растворения древесины в ионных жидкостях на основании уравнения Абрахама, которое, как показал Андерсон [6], успешно может характеризовать растворяющую способность ионных жидкостей по отношению к полимерам, а также влияние некоторых факторов на этот процесс. Установлено, что успешный перевод древесного вещества в растворенное состояние требует не только разрушения водородных связей в частично кристаллической целлюлозе, но и сольватирования лигнина, имеющего ароматическую природу.

Динамика растворения древесины в ионных жидкостях зависит от размеров частиц обрабатываемого образца и температуры обработки. Установлено [7], что в ионной жидкости легче растворить образцы, состоящие из более мелких частиц (эффективность растворения лигноцеллюлозных материалов в ионных жидкостях будет располагаться в следующем ряду: древесная мука после размола в шаровой мельнице > опилки > термомеханические волокна >> древесная щепа). Это объясняется не только большей площадью контакта жидкость - твердое, но и тем фактом, что размол древесины приводит к частичному разрушению структуры, в частности к разрушению алкиларильных лигноуглеводных связей. Повышенная температура (более $130^{\circ} \mathrm{C}$ ) позволяет перевести в растворенное состояние большее количество древесного вещества за меньшее время, однако может привести и к разрушению лигноцеллюлозных материалов.

Содержание воды в образце древесины играет значительную роль в определении ее растворимости в ионных жидкостях. Вода существенно снижает растворимость древесины [7].

Поскольку все исследователи утверждают, что компоненты древесины переходят в растворенное состояние в ионных жидкостях практически без разложения, то после растворения древесины в ионной жидкости отдельные ее компоненты могут быть выделены из раствора. Регенерация самой ионной жидкости позволяет использовать ее повторно. Анализ ИК-Фурье спектров выделенного лигнина показывает полное отсутствие в нем углеводов [7]. ЯМР-спектры выделенной из раствора целлюлозной составляющей позволяют охарактеризовать ее как лигноуглеводный комплекс с гораздо меньшим содержанием лигнина по сравнению с исходным образцом.

Практически все работы по растворению древесины выполнены с ионными жидкостями, катион которых представляет собой имидазолий с различными заместителями, и, как было отмечено ранее, использовались, как правило, хлориды замещенного имидазолия - наиболее доступные и хорошо изученные ионные жидкости. В работе [7] предпринята попытка сравнения растворяющей способности по отношению к древесине ионных жидкостей, отличающихся анионом. Было обнаружено, что ацетат 1-этил-3-метилимидазолия является лучшим растворителем для древесины (объектами обработки были Southern yellow pine и Red oak), чем хлорид 1-бутил-3-метилимидазолия, при обработке в течение 16 ч при 110 C.

Ацетат 1-бутил-3-метилимидазолия обладает большей сольватирующей способностью [8], более низкими температурой плавления, вязкостью, коррозионностью, токсичностью по сравнению с хлоридом [9] имидазолия с теми же заместителями.

Цель исследования - сравнительный анализ динамики растворения древесины в ионных жидкостях, отличающихся анионом (в ацетате и хлориде 1-бутил-3-метилимидазолия), и селективное выделение компонентов древесного вещества из раствора.

\section{Экспериментальная часть}

Для проведения исследования отбирали фракцию обессмоленной древесины ели обыкновенной (Picea abies) с размером частиц менее 1 мм. Влажность образца, определенная на анализаторе влажности SHIMADZU MOC-120H, составила 7,8\%. Обработку древесины проводили ионными жидкостями 1-бутил3-метилимидазолий ацетат и 1-бутил-3-метилимидазолий хлорид торговой марки SIGMA-ALDRICH в интервале температур 80-160 ${ }^{\circ} \mathrm{C}$ в течение заданного промежутка времени при перемешивании. Гидромодуль (соотношение: твердое - жидкость) во всех опытах составил 1 : 50, поскольку установлено положительное влияние увеличения гидромодуля на процесс растворения [7]. После обработки древесный остаток отделя- 
ли от жидкой фазы на стеклянном фильтре, промывали водой до нулевой оптической плотности при длине волны 209 нм [10], высушивали до постоянной массы и рассчитывали массу древесины, перешедшей в раствор (растворимость).

Регенерацию растворенных компонентов древесного вещества из фильтрата осуществляли последовательным осаждением смесью ацетон - вода и водой по методике [7]. Для полученных образцов на спектрометре IR Prestige-21 записывали ИК-спектры твердого образца методом нарушенного полного внутреннего отражения с применением стандартной автоматической коррекции спектров в диапазоне 550-4000 см ${ }^{-1}$. Молекулярную массу лигнинных образцов определяли методом ВЭЖХ на хроматографе «Стайер» со спектрофотометрическим детектором (колонки «Phenogel» размером $300 \times 7,8$ мм со стиролдивинилбензоловым гелем, элюент - диметилформамид (для хроматографии), содержащий 0,1 моль/л бромида лития с добавкой $1 \%$ уксусной кислоты).

\section{Обсуждение результатов}

Результаты изучения растворимости еловой древесины в ацетате и хлориде 1-бутил-3-метилимидазолия в интервале температур $80-160{ }^{\circ} \mathrm{C}$ при продолжительности обработки 2 ч представлены на рисунке 1. Из рисунка видно, что с ростом температуры растворимость древесины увеличивается в обеих ионных жидкостях. При более высоких температурах хлорид 1-бутил-3-метилимидазолия обладает лучшей растворяющей способностью, чем ацетат 1-бутил-3-метилимидазолия. Однако это происходит при температурах выше $140{ }^{\circ} \mathrm{C}$, которые могут оказать разрушающее действие на компоненты древесины, переходящие в раствор.

Изучение динамики растворения древесного вещества в ионных жидкостях при максимальной из выбранного диапазона температуре $160^{\circ} \mathrm{C}$ показало (рис. 2), что с увеличением продолжительности обработки растворимость древесины увеличивается в обоих случаях, при этом в ацетате 1-бутил-3метилимидазолия древесина растворяется значительно лучше. При использовании хлорида 1-бутил-3-метилимидазолия практически через 2 ч обработки растворимость достигает максимального значения и далее практически не изменяется. В работе [7] установлено, что для хвойной древесины (Southern yellow pine) при обработке в течение 16 ч при $110{ }^{\circ} \mathrm{C}$ в хлориде 1-этил-3-метилимидазолия растворилась примерно половина взятой навески древесины.

Проверка полноты растворения древесины в ацетате 1-бутил-3-метилимидазолия (опыт проведен в течение 24 ч при $160^{\circ} \mathrm{C}$ ) показала, что максимальная убыль массы древесины составила 94\%. Однако анализ молекулярно-массового распределения выделенного из раствора в ионной жидкости образца лигнина свидетельствует, что в этих условиях лигнин при переходе в раствор подвергается существенной дефрагментации (среднечисловая молекулярная масса $M_{\mathrm{n}}=2070$, среднемассовая молекулярная масса $M_{\mathrm{w}}=3720$ ).

Таким образом, ацетат 1-бутил-3-метилимидазолия обладает лучшей растворяющей способностью по отношению к еловой древесине, чем хлорид 1-бутил-3-метилимидазолия, при температурах, не вызывающих деструкцию компонентов древесины при переходе их в раствор, поэтому дальнейшие исследования проведены с использованием ацетата 1-бутил-3-метилимидазолия.

Поскольку было установлено, что растворение древесины в ионной жидкости при $160{ }^{\circ} \mathrm{C}$ происходит более полно, но при этом разрушаются полимеры (компоненты древесного вещества), переходящие в раствор, для изучения динамики растворения углеводной и лигнинной составляющей еловой древесины выбрали температуру $120^{\circ} \mathrm{C}$ и обрабатывали образцы в течение $1,2,4$ и 6 ч. Растворимость древесины в этих условиях составила от 13 до $28 \%$ (рис. 2).

Для регенерированных из раствора в ионной жидкости компонентов были записаны ИК-спектры, которые подтверждают углеводную и лигнинную природу образцов. В таблице 1 приведены характеристические полосы выделенных образцов, обнаруженные в спектрах.

В таблице 2 отражены результаты хроматографического анализа лигнина, выделенного из раствора при разной продолжительности процесса обработки древесины (для сравнения в таблице показаны характеристики полимолекулярных свойств малоизмененного елового лигнина - диоксанлигнина (ДЛ), выделяемого из древесины экстракцией диоксаном в мягких условиях по методу Пеппера [11]).

Как видно из таблицы 2, растворившийся при разной продолжительности обработки лигнин обладает практически одинаковыми свойствами (довольно полидисперсен, имеет близкие значения среднечисловых и среднемассовых молекулярных масс) и по этим характеристикам практически не отличается от лигнина, выделенного из древесины в мягких условиях. 


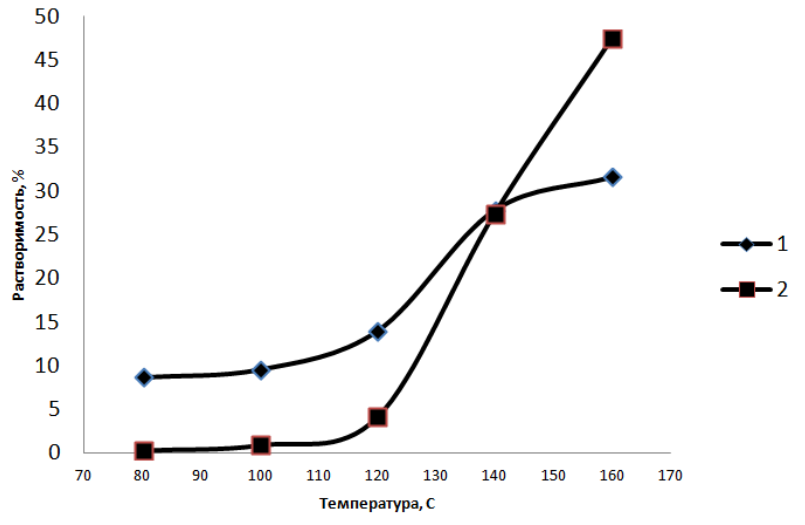

Рис. 1. Растворимость древесины в зависимости от температуры в ацетате 1-бутил-3-метилимидазолия (1) и хлориде 1-бутил-3-метилимидазолия (2)

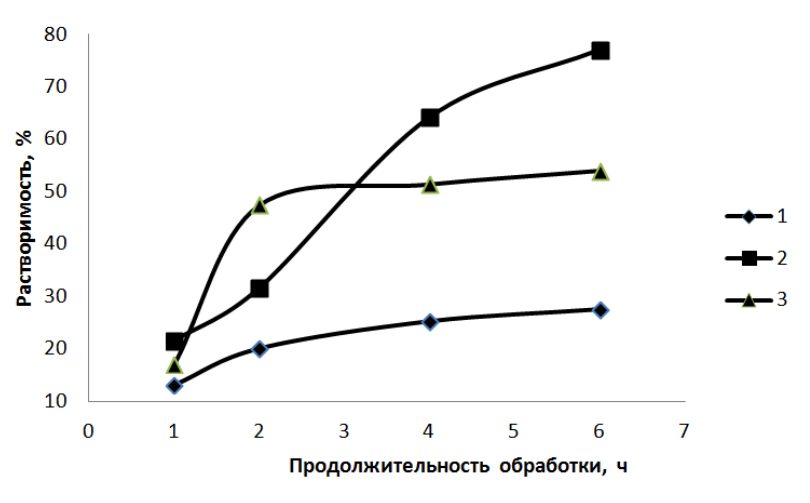

Рис. 2. Растворимость древесины в зависимости от продолжительности обработки в ацетате 1-бутил-3-метилимидазолия при температуре $120{ }^{\circ} \mathrm{C}(1)$, в ацетате 1-бутил-3-метилимидазолия (2) при $160{ }^{\circ} \mathrm{C}$, в хлориде 1-бутил-3-метилимидазолия при $160{ }^{\circ} \mathrm{C}$ (3)

Таблица 1. Характеристические полосы в ИК-спектрах регенерированных целлюлозы и лигнина

\begin{tabular}{|c|c|c|}
\hline \multirow{2}{*}{$\begin{array}{c}\text { Положение } \\
\text { полосы }\end{array}$} & \multicolumn{2}{|c|}{ Отнесение полосы } \\
\hline & целлюлоза & лигнин \\
\hline $3550-3100$ & $\begin{array}{c}v_{\mathrm{OH}} \text {, участвующих в меж- и внутримолекулярных } \\
\text { Н-связях }\end{array}$ & $\begin{array}{c}\text { O-Н валентные колебания (вовлеченные } \\
\text { в водородную связь ОН группы) }\end{array}$ \\
\hline $3000-2750$ & 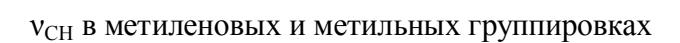 & $v_{\text {CH }}$ в метиленовых и метильных группировках \\
\hline $1738-1709$ & - & $\begin{array}{c}\mathrm{C}=\mathrm{O} \text { валентные колебания в неконъюгирован- } \\
\text { ных кетонах, карбонилах и сложноэфирных } \\
\text { группах }\end{array}$ \\
\hline $1650-1630$ & $\delta_{\mathrm{H}-\mathrm{O}-\mathrm{H}}$ колебания кристаллизационной воды & - \\
\hline $1515-1505$ & - & $\begin{array}{c}\text { C-C валентные ароматические скелетные } \\
\text { колебания }\end{array}$ \\
\hline 1470 & $\delta_{\mathrm{i}}(\mathrm{OH})+\delta(\mathrm{CH})$ & - \\
\hline 1374 & $\delta_{\mathrm{i}}(\mathrm{OH})+\delta(\mathrm{CH})+\gamma_{\odot}\left(\mathrm{CH}_{2}\right)$ & - \\
\hline 1337 & $\delta(\mathrm{OH})+\delta(\mathrm{CH})$ & - \\
\hline $1270-1266$ & - & скелетные колебания гваяцильного кольца \\
\hline 1260 & $\delta_{\mathrm{i}}(\mathrm{OH})+\delta(\mathrm{CH})+\gamma_{\Theta}\left(\mathrm{CH}_{2}\right)$ & - \\
\hline 1160 & $\delta(\mathrm{OH})+\delta(\mathrm{CH})$ & - \\
\hline $925-915$ & - & $\begin{array}{l}\text { C-Н внеплоскостные деформационные } \\
\text { колебания в ароматическом кольце }\end{array}$ \\
\hline 615 & (C-C) скелетные & - \\
\hline
\end{tabular}

Таблица 2. Характеристики полимолекулярных свойств лигнина

\begin{tabular}{c|c|c|c|c|c}
\hline$t$, ч & $M_{\mathrm{n}}$ & $M_{\mathrm{w}}$ & $M_{\mathrm{z}}$ & $M_{\mathrm{w}} / M_{\mathrm{n}}$ & $M M$ \\
\hline 1 & 6960 & 16360 & 28420 & 2,35 & 14850 \\
2 & 5600 & 14540 & 26060 & 2,60 & 13980 \\
4 & 7640 & 16850 & 30190 & 2,21 & 14180 \\
6 & 7720 & 17040 & 30460 & 2,21 & 14290 \\
ДЛ & 7080 & 15190 & 30710 & 2,14 & 10950 \\
\hline
\end{tabular}

Примечания: $t$ - продолжительность обработки древесины ионной жидкостью; $M_{\mathrm{n}}-$ среднечисловая молекулярная масса; $M_{\mathrm{w}}-$ среднемассовая молекулярная масса; $M_{\mathrm{z}}-Z$-средняя молекулярная масса; $M_{\mathrm{w}} / M_{n}-$ степень полидисперсности; $M M$ - молекулярная масса для наибольшего пика.

\section{Выводы}

1. Установлено, что ацетат 1-бутил-3-метилимидазолия обладает лучшей растворяющей способностью в отношении древесины, чем хлорид 1-бутил-3-метилимидазолия, в диапазоне температур 80-135 ${ }^{\circ} \mathrm{C}$; на процесс растворения положительно влияет увеличение температуры и продолжительности обработки. 
2. Регенерированные из раствора древесины в ИЖ препараты представляют собой целлюлозу и лигнин, что подтверждают полученные ИК-спектры образцов.

3. Лигнин переходит в раствор при обработке ацетатом 1-бутил-3-метилимидазолия равномерно, поскольку молекулярные массы и степень полидисперсности его практически не зависят от продолжительности обработки.

\section{Сиисок литературы}

1. Han Sh., Li J., Zhu Sh., Chen R., Wu Y., Zhang X., Yu Z. Potential applications of ionic liquids in wood related industries // BioResources. 2009. Vol. 4, N2. Pp. 576-601.

2. Alma M.H., Acemioglu B.A. Kinetic study of sulfuric acid-catalyzed liquefaction of wood into phenol // Chem. Eng. Commun. 2004. Vol. 191. Pp. 968-980.

3. Capart R., Rezzoug S.A. Assesment of wood liquefaction in acidified ethylene glycol using experimental design methodology // Energy Conversion Manage. 2003. Vol. 44. Pp. 781-792.

4. Hie H., Shi T. Wood liquefaction by ionic liquids // Holzforschung. 2006. Vol. 60. Pp. 509-512.

5. Kilpelainen I., Xie H., King A., Granstrom M., Heikkinen S., Argyropoulos D.S.J. Dissolution of wood in ionic liquids // J. Agric. Food Chem. 2007. Vol. 55. Pp. 9142-9148.

6. Anderson J.L., Ding J., Welton T., Armstrong D.W. Characterizing ionic liquidson the basis of multiple salvation interaction// J. Am. Chem. Soc. 2002. Vol. 124. Pp. 14253-14254.

7. Sun N., Rahman M., Maxim M.L., Rodriguez H., Rorgers R.D. Complete dissolution and partial delignification of wood in the ionic liquid 1-ethyl-3-methylimidazolium acetate // Green Chemistry. 2009. Vol. 11. Pp. 646-655.

8. Wu Y., Sasaki T., Irie S., Sakurai K. A novel biomass-ionic liquid platform for utilization of native chitin // Polymer. 2008. Vol. 49. Pp. 2321-2327.

9. [Электронный ресурc]. URL: http://www.sigmaaldrich.com/catalog/search/Productdetail/ALDRICH/672041.

10. Махова Т.А., Боголицын К.Г., Скребец Т.Э. Физико-химические свойства ацетата 1-бутил-3-метилимидазолия // Журнал общей химии. 2009. Т. 79, №1. С. 128-131.

11. Браунс Ф.Э., Браунс Д.А. Химия лигнина. М., 1964. 540 с.

Поступило в редакичию 18 февраля 2016 г.

После переработки 14 марта 2016 г. 
Skrebets T.E. ${ }^{*}$, Ivakhnov A.D. DISSOLUTION OF WOOD IN THE IMIDAZOLIUM IONIC LIQUIDS

Northern (Arctic) federal university of M. V. Lomonosov, Severnaya Dvina Embankment, 17, Arkhangelsk, 163002

(Russia),e-mail: tskrebets@mail.ru

Dynamics of dissolution of fir-tree wood in ionic liquids acetate 1-buthyl-3-methylimidazolium and chloride 1-buthyl3-methylimidazolium in the range of temperatures from 80 to $160^{\circ} \mathrm{C}$ has been studied. It was established that acetate 1-buthyl3-methylimidazolium possesses the best dissolving ability in relation to wood, than chloride 1-buthyl-3-methylimidazolium, at temperatures of $80-135^{\circ} \mathrm{C}$. Above $160^{\circ} \mathrm{C}$ fir-tree wood was almost completely dissolved in acetate 1-buthyl-3-methylimidazolium, however dissolution of wood at this temperature leads to destruction of its components. From the solution received by wood processing by acetate 1-buthyl-3-methylimidazolium at $120^{\circ} \mathrm{C}$ within 2 hours lignin and carbohydrate fractions were allocated selectively. IR spectrums of the regenerated samples were similar to the corresponding wood components. The analysis of polymolecular properties of lignin regenerated from solution has shown that there was no any polymer destruction under these conditions. Molecular mass and polydispersion degree were closed to the dioxanlignin allocated from wood by dioxane extraction in soft conditions.

Keywords: wood, ionic liquids, dissolution, temperature, lignin, cellulose.

\section{References}

1. Han Sh., Li J., Zhu Sh., Chen R., Wu Y., Zhang X., Yu Z. BioResources, 2009, vol. 4, no. 2, pp. 576-601.

2. Alma M.H., Acemioglu B.A. Chem. Eng. Commun., 2004, vol. 191, pp. 968-980.

3. Capart R., Rezzoug S.A. Energy Conversion Manage, 2003, vol. 44, pp. 781-792.

4. Hie H., Shi T. Holzforschung, 2006, vol. 60, pp. 509-512.

5. Kilpelainen I., Xie H., King A., Granstrom M., Heikkinen S., Argyropoulos D.S.J. J. Agric. Food Chem., 2007, vol. 55, pp. 9142-9148.

6. Anderson J.L., Ding J., Welton T., Armstrong D.W. J. Am. Chem. Soc., 2002, vol. 124, pp. 14253-14254.

7. Sun N., Rahman M., Maxim M.L., Rodriguez H., Rorgers R.D. Green Chemistry, 2009, vol. 11, pp. 646-655.

8. Wu Y., Sasaki T., Irie S., Sakurai K. Polymer, 2008, vol. 49, pp. 2321-2327.

9. [Electronic resource]. URL: http://www.sigmaaldrich.com/catalog/search/Productdetail/ALDRICH/672041.

10. Makhova T.A., Bogolitsyn K.G., Skrebets T.E. Zhurnal obshchei khimii, 2009, vol. 79, no. 1, pp. 128-131. (in Russ.).

11. Brauns F.E., Brauns D.A. Khimiia lignina. [Chemistry of lignin]. Moscow, 1964, 540 p. (in Russ.).

Received February 18, 2016

Revised March 14, 2016

\footnotetext{
* Corresponding author.
} 